\title{
Blood glucose, plasma insulin and sensory responses to guar- containing wheat breads: effects of molecular weight and particle size of guar gum
}

\author{
BY PETER R. ELLIS* AND FATHY M. DAWOUD \\ Department of Food and Nutritional Sciences, King's College London (University of London), \\ Campden Hill Road, London W8 7 AH \\ AND EDWIN R. MORRIS \\ Department of Food Research and Technology, Silsoe College, Silsoe, Bedford MK45 4DT
}

(Received 5 July 1990 - Accepted 5 March 1991)

\begin{abstract}
The effectiveness of guar gum in reducing post-prandial blood glucose and plasma insulin levels in human subjects seems to depend mainly on its ability to increase the viscosity of digesta in the small intestine. However, the precise relationship between the rheological properties of guar gum (either in vitro or in vivo) and the changes in blood metabolites and hormones is unknown. The aim of the present study, therefore, was to investigate the effects of wheat breads containing guar gum samples varying in molecular weight $\left(M_{w}\right)$ and particle size (characteristics that strongly influence the rheological properties of guar gum) on post-prandial blood glucose and plasma insulin levels in healthy subjects. The sensory qualities of breads containing guar-gum flours of different $\mathbf{M}_{w}$ were also evaluated using a hedonic scoring technique. No significant differences in the post-prandial blood glucose responses were found between the control and guar breads. However, all the guar breads elicited significant $(P<0.05)$ decreases in the post-prandial rise in plasma insulin, an effect that did not appear to be influenced by large variations in $M_{w}$ or particle size of guar gum. Moreover, the sensory qualities of guar bread were markedly improved by using low $M_{w}$ grades of guar gum.
\end{abstract}

Carbohydrate metabolism: Sensory analysis: Guar gum: Dietary fibre

It is now well known that the addition of guar gum (a galactomannan extract of the Indian Cluster bean) to either glucose drinks or carbohydrate-rich meals reduces the post-prandial rise in blood glucose and plasma insulin in healthy and diabetic subjects (Jenkins et al. 1976, 1977; Jarjis et al. 1984; Morgan et al. 1985; Ellis et al. 1988 b). Moreover, long-term improvements in carbohydrate and lipid metabolism of patients with insulin-dependent diabetes (IDDM) and non-insulin-dependent diabetes (NIDDM) have been achieved using either pharmaceutical preparations of guar gum or guar-containing foods (Aro et al. 1981; Peterson et al. 1987; Ebling et al. 1988). There is still, however, a lack of information about the types, doses and mode of administration of guar gum that should be used to optimize its metabolic effects (Ellis et al. 1986; Fairchild et al. 1990).

The physiological action of guar gum seems to depend mainly on the capacity of guar gum to hydrate rapidly and thus increase the viscosity of digesta in the stomach and small intestine (Blackburn et al. 1984; Edwards \& Read, 1990; Roberts et al. 1990a, b). High viscosity in the small intestine is known to slow down the digestion and absorption of carbohydrate, which then leads to a reduction in post-prandial hyperglycaemia (Blackburn

\footnotetext{
* For reprints.
} 
et al. 1984; Edwards \& Read, 1990). The rheological (flow) properties of guar gum are dependent on the concentration and molecular weight $\left(\mathrm{M}_{\mathrm{w}}\right)$ of the galactomannan in the guar-gum preparation, and also on the size-distribution of the guar-gum particles, which strongly influences its rate of hydration (Seaman, 1980; Ellis \& Morris, 1991). The slow hydration rate and low ultimate viscosity (in vitro) of some guar-gum preparations (O'Connor et al. 1981; Ellis \& Morris, 1991) may provide an explanation of their lack of effect in improving blood glucose control (Holman et al. 1987; Baker, 1988). However, it is still not known if and how the particle-size distribution and, therefore, hydration rate of guar gum will influence post-prandial changes in gut function and carbohydrate tolerance. Furthermore, the relationship between the rheological properties of guar gum and the changes in post-prandial blood glucose and plasma insulin levels has not been fully investigated. One way of studying this is to use grades of guar gum containing galactomannan chains of low average $M_{w}$ which, when fully hydrated, produce solutions of low viscosity.

The present study was designed to examine the effects of wheat breads containing samples of guar gum varying in $\mathrm{M}_{\mathrm{w}}$ and particle size on the post-prandial rise in blood glucose and plasma insulin in non-diabetic subjects. A formal sensory analysis trial was also undertaken, using a standard hedonic rating method, to evaluate the effect of $M_{w}$ of guar gum on the palatability of wheat bread. It is known from previous studies (Ellis et al. 1981, $1988 a$ ) that a high viscosity grade of guar gum depresses the overall hedonic rating of wheat bread at guar gum concentrations $>32 \mathrm{~g} / \mathrm{kg}$ bread, but the specific sensory attributes of bread that are impaired have not been identified. Therefore, in the present work we have studied the effects of guar-gum flours of different $M_{w}$ on the hedonic ratings of texture, flavour and colour as well as on overall quality.

\section{MATERIALS AND METHODS}

\section{Guar-gum grades and physicochemical characteristics}

Standard food grades of high (M150), medium (M90) and low (M60) $\mathrm{M}_{\mathrm{w}}$ guar-gum flours (Meyprogat range: Meyhall Chemical Company Ltd, Switzerland) and a pharmaceutical preparation of granulated guar gum (Guarem, Rybar Laboratories, Amersham, Bucks.) were selected for study. The latter, a guar gum of large particle size (the coarse Guarem sample), was milled using a ball-mill to produce samples of smaller particle size distribution (i.e. the medium and fine fractions).

The particle-size distributions of all the guar-gum preparations were determined in duplicate by a standard laboratory sieve method (Lauer, 1966) and are presented in Fig. 1 as the percentage cumulative oversize $v$. log of particle size $(\mu \mathrm{m})$.

The average molecular weights of the guar-gum samples were estimated from measurements of intrinsic viscosity, $[\eta]$. Fully hydrated dilute solutions of each sample were prepared, and relative viscosity $\left(\eta_{\mathrm{r}: \mathrm{s}}\right)$ was measured over a range of concentrations (such that $1.2<\eta_{\mathrm{rel}}<2.0$ ) on a Contraves Low Shear 30 viscometer in the 'Newtonian plateau' region where viscosity is independent of shear rate. Intrinsic viscosities were obtained by combined extrapolation (Morris, 1984) of $\left(\eta_{\mathrm{rel}}-1\right) / \mathrm{c}$ and $\ln \left(\eta_{\mathrm{rel}}\right) / \mathrm{c}$ to zero concentration (c), and $M_{w}$ was then calculated by the Mark-Houwink relationship

$$
[\eta]=K M^{\alpha},
$$

using reported values (Robinson et al. 1982) of $\alpha 0.723$ and $K 3.8 \times 10^{-4} \mathrm{~d} 1 / \mathrm{g}$. The intrinsic viscosity and calculated $\mathbf{M}_{\mathbf{w}}$ for each sample are listed in Table 1.

Hydration rates of all the guar-gum samples (Fig. 2) were determined by mixing each sample in distilled water to produce a $10 \mathrm{~g}$ guar gum (dry weight)/1 dispersion and 


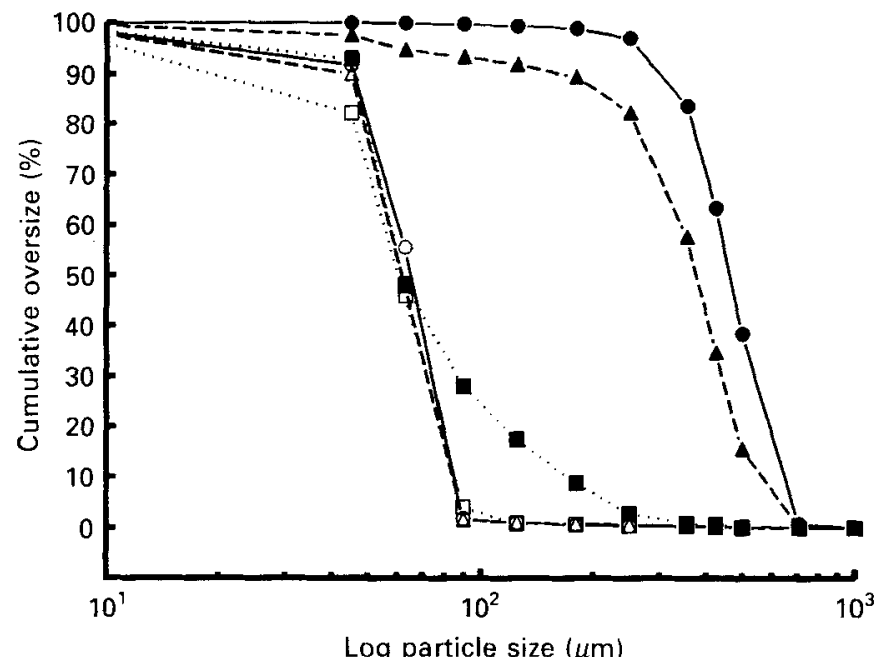

Fig. 1. Cumulative oversize (\%) v. $\log$ particle size distribution $(\mu \mathrm{m})$ of $\mathrm{M} 150\left(-\mathrm{O}_{-}\right)$, M90 (-- $\left.\triangle_{--}\right)$and $\mathrm{M} 60$ $\left(\cdots[\cdots)\right.$ guar-gum flours: and coarse $(-\mathbf{-}-)$, medium $\left(-\boldsymbol{\Delta}_{--}\right)$and fine $(\cdots \square \cdots)$ Guarem samples. Experimental points are means of duplicates. For details of guar-gum flours and Guarem samples, see p. 364 and Table 1.

Table 1. Intrinsic viscosity $[\eta]$ and molecular weight $\left(M_{w}\right)$ of guar-gum samples

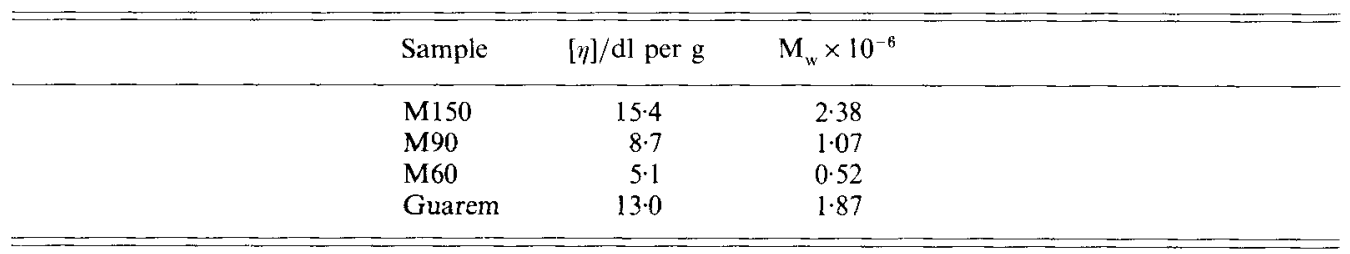

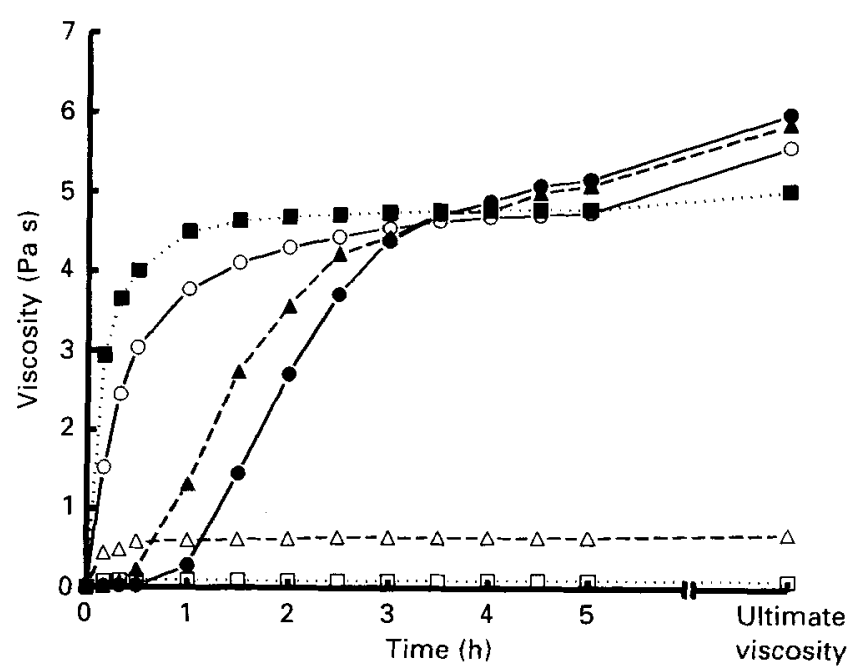

Fig. 2. Development of viscosity (Pa s) over 5 h of M150 (-O-), M90 (-- $\triangle--)$ and M60 ( $\cdots \square \cdots)$ guar-gum flours; and coarse $(-\mathbf{-}-)$, medium $\left(--\mathbf{A}^{--}\right)$and fine $(\cdots, \cdots)$ Guarem samples. For definition of ultimate viscosity, see pp. 364 and 366. Experimental points are means of duplicates. For details of guar-gum flours and Guarem samples, see p. 364 and Table 1. 
monitoring changes in viscosity at $25^{\circ}$ over $5 \mathrm{~h}$ using a Brookfield Synchro-Lectric RVT viscometer (spindle 4, speed $20 \mathrm{rev} . / \mathrm{min}$ ). An additional viscosity measurement was taken on dispersions in which the guar gum had been completely hydrated (i.e. 'ultimate' viscosity). This was achieved by leaving the guar gum to hydrate for $24 \mathrm{~h}$ and then homogenizing the dispersions using an Ultra-Turrax mixer. Two hydration tests were carried out on each guar-gum sample. Full details of this method have been published elsewhere (Ellis \& Morris, 1991).

\section{Bread preparation (for physiological and sensory studies)}

Control and guar-containing wheat breads were prepared in the form of small rolls using the Chorleywood bread process (Apling \& Ellis, 1982) and a simple lean recipe consisting of white wheat flour (Sovereign; Allied Mills, London EC3R 7PE), salt, fat (hydrogenated vegetable oil), yeast and variable amounts of water depending on the viscosity of the guar gum (Ellis \& Apling, 1983). Guar-gum samples were incorporated into the recipe as a replacement for wheat flour at the $100 \mathrm{~g} / \mathrm{kg}$ level of replacement. At $2-3 \mathrm{~h}$ after baking, the bread rolls were frozen rapidly to $-30^{\circ}$ using a blast freezer and then stored at $-20^{\circ}$ for use throughout the period of the physiological study. For the sensory analysis trial the breads were prepared the evening before each tasting session and stored for $12 \mathrm{~h}$ in sealed polyethylene bags.

\section{Composition of control and guar-gum meals}

The wheat flours and guar-gum samples were analysed for moisture, lipid (Soxhlet; light petroleum (b.p. $40-60^{\circ}$ )-diethyl ether extraction), protein (Kjeldahl; nitrogen $\times 5 \cdot 7$ ), crude fibre (guar gum only) and ash by standard methods (Egan et al. 1981); the 'available' carbohydrate (mainly starch) of wheat flour and the galactomannan of guar gum were estimated by difference. The galactomannan content of the M150, M90, M60 and Guarem samples were $847,844,811$ and $820 \mathrm{~g} / \mathrm{kg}$ guar gum respectively. The compositions of the breads (Table 2) were calculated from the proximate analysis values for the wheat flour and guar-gum samples, and from food table values (Paul \& Southgate, 1978) for the rest of the ingredients; the dietary fibre content of the wheat flour was obtained from Englyst et al. (1982).

The meals used for the physiological study consisted of two toasted wheat-bread rolls, $15 \mathrm{~g}$ salted butter (Anchor), $38 \mathrm{~g}$ strawberry jam (Robinson's) and an amount of carbonated mineral water (Perrier) to make up a total meal weight of $300 \mathrm{~g}$, of which $75 \mathrm{~g}$ was 'available' carbohydrate. The weight of the bread portions varied depending on the type of guar gum used in the recipe but always contained 7.6 g guar gum (except the control which was guar-gum-free) and $50 \mathrm{~g}$ 'available' carbohydrate (mostly starch). The strawberry jam provided about $25 \mathrm{~g}$ 'available' carbohydrate (mostly sucrose), which was analysed by a refractometric method (Egan et al. 1981).

\section{Physiological study}

Subjects and ethical approval. Seventeen non-diabetic subjects (fourteen males and three females; 18-29 years; mean body mass index (weight/height ${ }^{2}$ ) 22.8 (sEM $0 \cdot 7$, range $18 \cdot 5-26 \cdot 1) \mathrm{kg} / \mathrm{m}^{2}$ ) were recruited from King's College London. The study was approved by the King's College Ethical Committee.

Experimental design and procedure. All subjects were required to eat, after an overnight fast, seven types of wheat bread (one control and six types of guar bread; Table 2) in random order on separate days (at least $3 \mathrm{~d}$ apart). On each test day $10 \mathrm{ml}$ samples of venous blood were taken from the fasted subjects who were then required to eat a breakfast 
Table 2. Composition $(\mathrm{g} / \mathrm{kg}$ ) of control and guar breads (by calculation)

\begin{tabular}{|c|c|c|c|c|c|c|c|c|c|}
\hline \multirow[b]{2}{*}{ Bread type* } & \multirow[b]{2}{*}{$\begin{array}{l}\text { Guar } \\
\text { gum }\end{array}$} & \multirow[b]{2}{*}{ Moisture } & \multirow[b]{2}{*}{ Protein } & \multirow[b]{2}{*}{ Fat } & \multirow[b]{2}{*}{ Ash } & \multicolumn{3}{|c|}{ Total carbohydrate } & \multirow{2}{*}{$\begin{array}{c}\text { Total } \\
\text { energy } \\
(\mathrm{kJ} / \mathrm{kg}) \S\end{array}$} \\
\hline & & & & & & $\begin{array}{c}\text { Galactomannan } \\
\text { (from guar gum) }\end{array}$ & $\begin{array}{l}\text { Cereal } \\
\text { fibre } \dagger\end{array}$ & $\begin{array}{c}\text { Available } \\
\text { carbohydrate }\end{array}$ & \\
\hline Control & 0 & 363 & 73 & 17 & 17 & 0 & 22 & 508 & 10810 \\
\hline \multicolumn{10}{|l|}{ Guar-gum flours } \\
\hline M150 (high $\mathrm{M}_{w}$ ) & 55 & 496 & 54 & 12 & 14 & 47 & 17 & 360 & 7700 \\
\hline $\mathrm{M} 90\left(\right.$ medium $\left.\mathrm{M}_{w}\right)$ & 59 & 460 & 58 & 13 & 15 & 50 & 18 & 386 & 8260 \\
\hline $\mathrm{M} 60\left(\right.$ low $\left.\mathrm{M}_{\mathrm{w}}\right)$ & 62 & 430 & 61 & 14 & 18 & 50 & 18 & 409 & 8750 \\
\hline \multicolumn{10}{|l|}{ Guarem } \\
\hline Coarse PS & 59 & 460 & 58 & 14 & 15 & 48 & 17 & 388 & 8330 \\
\hline Medium PS & 59 & 460 & 58 & 14 & 15 & 48 & 17 & 388 & 8330 \\
\hline Fine PS & 56 & 487 & 55 & 13 & 14 & 46 & 17 & 368 & 7890 \\
\hline
\end{tabular}

PS, particle size; $\mathrm{M}_{\mathrm{w}}$, molecular weight.

* Guar-gum bread types contained guar gum at the $100 \mathrm{~g} / \mathrm{kg}$ level of replacement of wheat flour; for details of preparation, see p. 366.

$\dagger$ Average value for non-starch polysaccharides in wheat flour, taken from Englyst et al. (1982).

$\$$ Starch, dextrins and sugars; calculated by difference: $1000-$ (moisture + protein + fat + ash + total dietary fibre).

$\S$ Includes a value for available carbohydrate expressed as monosaccharide.

meal. Further $10 \mathrm{ml}$ post-prandial blood samples were taken from the subjects $30,60,90$ and 120 min after the meal had commenced. The subjects were expected to consume their meals at approximately the same rate, and within a $12 \mathrm{~min}$ period; mean eating time was $7 \cdot 8$ (SEM $0 \cdot 4$, range $6-10$ ) $\mathrm{min}$.

Glucose and insulin assays. Blood glucose was measured by a standard glucose oxidase (EC 1.1.3.4) method (Werner et al. 1970) using a Boehringer Mannheim kit (Boehringer Mannheim House, Bell Lane, Lewes, East Sussex BN7 1LG) following deproteinization by trichloroacetic acid. Plasma insulin was measured by a double-antibody radioimmunoassay method (Soeldner \& Slone, 1965) with a standard kit (Amersham International plc, Lincoln Place, Green End, Aylesbury, Bucks. HP20 2TP). Interassay coefficients of variation of the quality-control samples for the glucose and insulin assays were 2.9 and $7.1 \%$ respectively.

Statistical analysis. Blood glucose and plasma insulin increments (changes relative to fasting values) were calculated at 30,60,90 and $120 \mathrm{~min}$. Integrated insulin increments were estimated by calculation of area under the curve (trapezoid rule). Insulin values below the fasting level were treated as zero. Differences between bread types were analysed by repeated measures analysis of variance (ANOVA) with a SAS statistical package (SAS Institute Inc., 1985). Significant differences between the control and the guar breads were accepted at $P<0.05$. Regression analysis was performed by the method of least squares using SAS statistical package (SAS Institute Inc., 1985).

\section{Sensory analysis}

Subjects and methods. Thirty-three naive assessors were recruited from King's College London. They were classified as naive assessors inasmuch as they had no previous experience of tasting the experimental bread samples and no previous knowledge of the experimental protocol. The assessors were asked to indicate their degree of liking for control and guar-bread rolls (containing high-, medium- and low- $\mathrm{M}_{\mathrm{w}}$ grades of guar gum) by marking a series of $100 \mathrm{~mm}$ unstructured scales labelled with appropriate anchor phrases (i.e. 'like extremely' and 'dislike extremely'). These scales are a continuous line 
version of the hedonic scale (Land \& Shepherd, 1988). Four analogue scales were included on one evaluation sheet so that assessors could record an overall hedonic rating, and ratings for specific attributes, namely texture, flavour and colour. The assessors were instructed to score flavour on the basis of the aroma and taste of the samples, and to score texture on the basis of touch and mouth-feel.

Experimental design and procedure. A repeated measures design was used, such that each assessor tasted five types of bread (two controls and the three guar gum types; Table 2) in random order at a single sitting. The two controls were prepared from identical recipes but different batches and were included in the design to provide information on variations between batches and order of presentation. The bread rolls were presented as fresh samples (baked the previous evening) with the assessors' choice of fat spread (salted or unsalted butter or Flora margarine). Still mineral water was provided for rinsing the mouth between each taste. A separate evaluation sheet was used for each bread sample tasted. The previously described procedure was repeated on a separate occasion ( 1 week later) with bread samples that had been toasted for a standard period of time, so that each sample was tasted in a form preferred by the individual assessor (i.e. hot or cold, lightly or darkly toasted).

Statistical analysis. The hedonic responses were measured in $\mathrm{mm}$ ranging from $100 \mathrm{~mm}$ for 'like extremely' to $0 \mathrm{~mm}$ for 'dislike extremely'. Differences in the hedonic score between bread types were analysed by parametric statistics using repeated measures ANOVA (SAS Institute Inc., 1985). Significant differences between the control and guar breads were accepted at $P<0.05$. The two main assumptions in using such an analysis are that the scales produce true interval data and that the data are normally distributed (Land \& Shepherd, 1988). It has been suggested previously that hedonic data derived from continuous line scales are suitable for parametric statistical analysis (Thomson \& McEwan, 1985). However, to test the conclusions from the parametric analysis the hedonic ratings were ranked and then analysed by repeated measures ANOVA (equivalent to using a nonparametric technique).

\section{RESULTS}

\section{Physiological study}

Glucose. Fasting blood levels were found to be within the normal range (pooled mean of all fasting values was 3.6 (SEM $0 \cdot 1$ ) mmol/1). Post-prandial rises in blood glucose relative to fasting in response to control and guar-gum meals were small; mean blood glucose increments were not more than $1.2 \mathrm{mmol} / \mathrm{l}$ at the peak post-prandial time $(30 \mathrm{~min})$ and close to or slightly below the baseline thereafter (Table 3 ). Responses to all the meals at all post-prandial time-intervals were similar, except for the $60 \mathrm{~min}$ time-interval at which we observed an attenuated response following the guar-bread meals relative to the control. However, these falls in glucose were not statistically significant. ANOVA did not indicate a within-subjects main effect of the bread meals either when all the post-prandial timeintervals were included in the analysis (Wilks' lambda $0.34 ; F$ ratio 0.78 on 6 and $11 \mathrm{df}$, $P<0.6$ ) or at $60 \mathrm{~min}$ only (Wilks' lambda $0.46 ; F$ ratio 2.1 on 6 and $96 \mathrm{df}, P<0.3$ ).

Insulin. Fasting plasma levels were slightly above normal during the experimental period (pooled mean of all fasting values was 17.7 (SEM 3.2) $\mathrm{mU} / 1$, due to elevated levels of two subjects; one of these had a mean fasting level of 63.1 (SEM 3.7) $\mathrm{mU} / 1$ ). A mean fasting value of 14.8 (SEM 1.5) $\mathrm{mU} / 1$ was obtained when this subject was omitted from the analysis. ANOVA revealed a significant main effect of bread (Wilks' lambda $0.34 ; F$ ratio 3.5 on 6 and $11 \mathrm{df}, P<0.03$ ). All six types of guar bread produced significantly lower insulin responses than the control when all four post-prandial time-intervals were included in the analysis (Table 4). At $60 \mathrm{~min}$, all the guar breads produced significant reductions in 
Table 3. Blood glucose increments relative to fasting values at four post-prandial time intervals in response to control and guar-bread meals

(Mean values with their standard errors for seventeen subjects)

\begin{tabular}{|c|c|c|c|c|c|c|c|c|}
\hline \multirow[b]{3}{*}{ Bread type* } & \multicolumn{8}{|c|}{ Glucose increments $(\mathrm{mmol} / \mathrm{l})$ at four post-prandial times $(\mathrm{min})$} \\
\hline & \multicolumn{2}{|c|}{30} & \multicolumn{2}{|c|}{60} & \multicolumn{2}{|c|}{90} & \multicolumn{2}{|c|}{120} \\
\hline & Mean & SEM & Mean & SEM & Mean & SEM & Mean & SEM \\
\hline Control & $1 \cdot 1$ & $0 \cdot 2$ & $0 \cdot 2$ & $0 \cdot 2$ & $-0 \cdot 2$ & $0 \cdot 2$ & $-0 \cdot 2$ & $0 \cdot 2$ \\
\hline $\begin{array}{l}\text { Guar-gum flours } \\
\text { M150 (high } \mathrm{M}_{w} \text { ) } \\
\text { M90 (medium } \mathrm{M}_{\mathrm{w}} \text { ) } \\
\text { M60 (low } \mathrm{M}_{\mathrm{w}} \text { ) }\end{array}$ & $\begin{array}{l}1 \cdot 1 \\
1 \cdot 1 \\
1 \cdot 2\end{array}$ & $\begin{array}{l}0 \cdot 2 \\
0 \cdot 1 \\
0 \cdot 2\end{array}$ & $\begin{array}{c}-0 \cdot 2 \\
-0 \cdot 4 \\
0\end{array}$ & $\begin{array}{l}0 \cdot 1 \\
0 \cdot 1 \\
0 \cdot 3\end{array}$ & $\begin{array}{c}-0 \cdot 4 \\
-0 \cdot 3 \\
0\end{array}$ & $\begin{array}{l}0 \cdot 1 \\
0 \cdot 1 \\
0 \cdot 2\end{array}$ & $\begin{array}{c}0 \\
-0 \cdot 2 \\
-0 \cdot 2\end{array}$ & $\begin{array}{l}0 \cdot 2 \\
0 \cdot 1 \\
0 \cdot 2\end{array}$ \\
\hline $\begin{array}{l}\text { Guarem } \\
\text { Coarse PS } \\
\text { Medium PS } \\
\text { Fine PS }\end{array}$ & $\begin{array}{l}0.9 \\
1.2 \\
0.8\end{array}$ & $\begin{array}{l}0 \cdot 2 \\
0 \cdot 2 \\
0 \cdot 2\end{array}$ & $\begin{array}{l}-0 \cdot 2 \\
-0 \cdot 1 \\
-0.3\end{array}$ & $\begin{array}{l}0 \cdot 2 \\
0 \cdot 2 \\
0 \cdot 2\end{array}$ & $\begin{array}{l}-0 \cdot 3 \\
-0 \cdot 1 \\
-0 \cdot 3\end{array}$ & $\begin{array}{l}0 \cdot 1 \\
0 \cdot 1 \\
0 \cdot 1\end{array}$ & $\begin{array}{l}-0 \cdot 1 \\
-0 \cdot 1 \\
-0 \cdot 2\end{array}$ & $\begin{array}{l}0 \cdot 1 \\
0 \cdot 1 \\
0 \cdot 1\end{array}$ \\
\hline
\end{tabular}

PS, particle size; $M_{w}$, molecular weight.

* Guar-gum bread types contained guar gum at the $100 \mathrm{~g} / \mathrm{kg}$ level of replacement of wheat flour; for details of composition, see Table 2, and for details of preparation, see p. 366 .

Table 4. Plasma insulin increments relative to fasting values at four post-prandial time intervals and integrated insulin values calculated from area under curve $(A U C)$ in response to control and guar-bread meals

(Mean values with their standard errors for seventeen subjects)

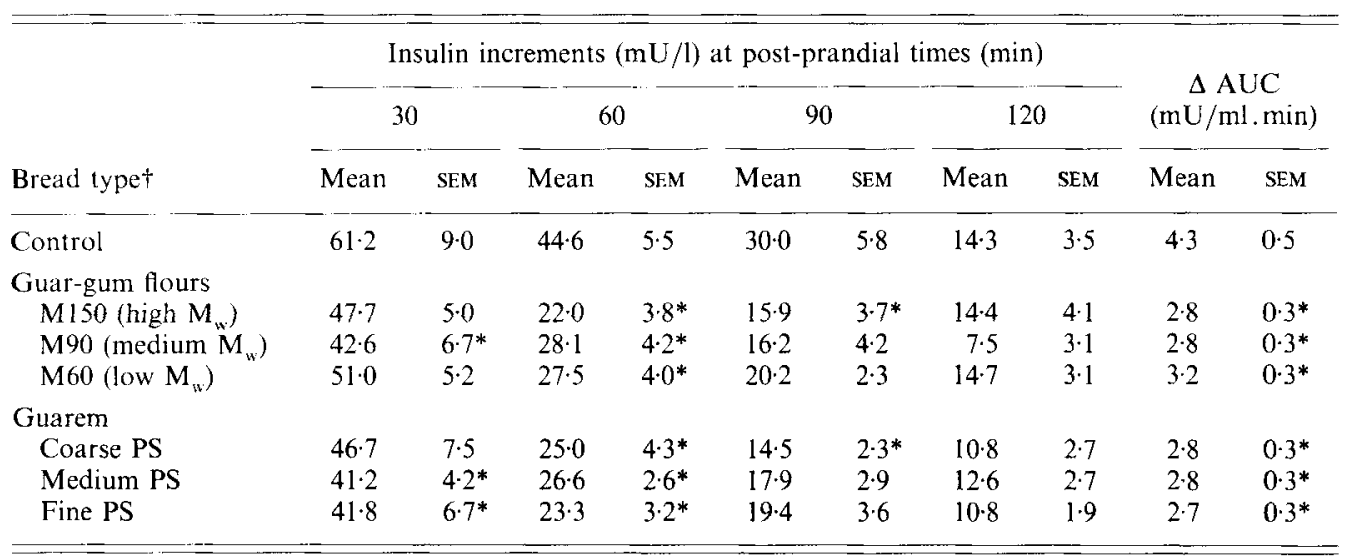

PS, particle size; $\mathrm{M}_{\mathrm{w}}$, molecular weight; $\triangle \mathrm{AUC}$, incremental area under the $2 \mathrm{~h}$ insulin curve.

* Mean values for experimental breads were significantly different from those for the control: $P<0.05$.

$\uparrow$ Guar-gum bread types contained guar gum at the $100 \mathrm{~g} / \mathrm{kg}$ level of replacement of wheat flour; for details of composition, see Table 2 , and for details of preparation, see p. 366 .

insulin compared with the control. Significant decreases in insulin at 30 and 90 min were also found, but only for the specific guar breads indicated in Table 4 . No significant differences were found at $120 \mathrm{~min}$.

Analysis of the mean integrated insulin levels $(\mathrm{mU} / \mathrm{ml} . \mathrm{min})$ also showed a significant main effect of bread (Wilks' lambda $0.35 ; F$ ratio 3.3 on 6 and $11 \mathrm{df}, P<0 \cdot 04$ ). Integrated 

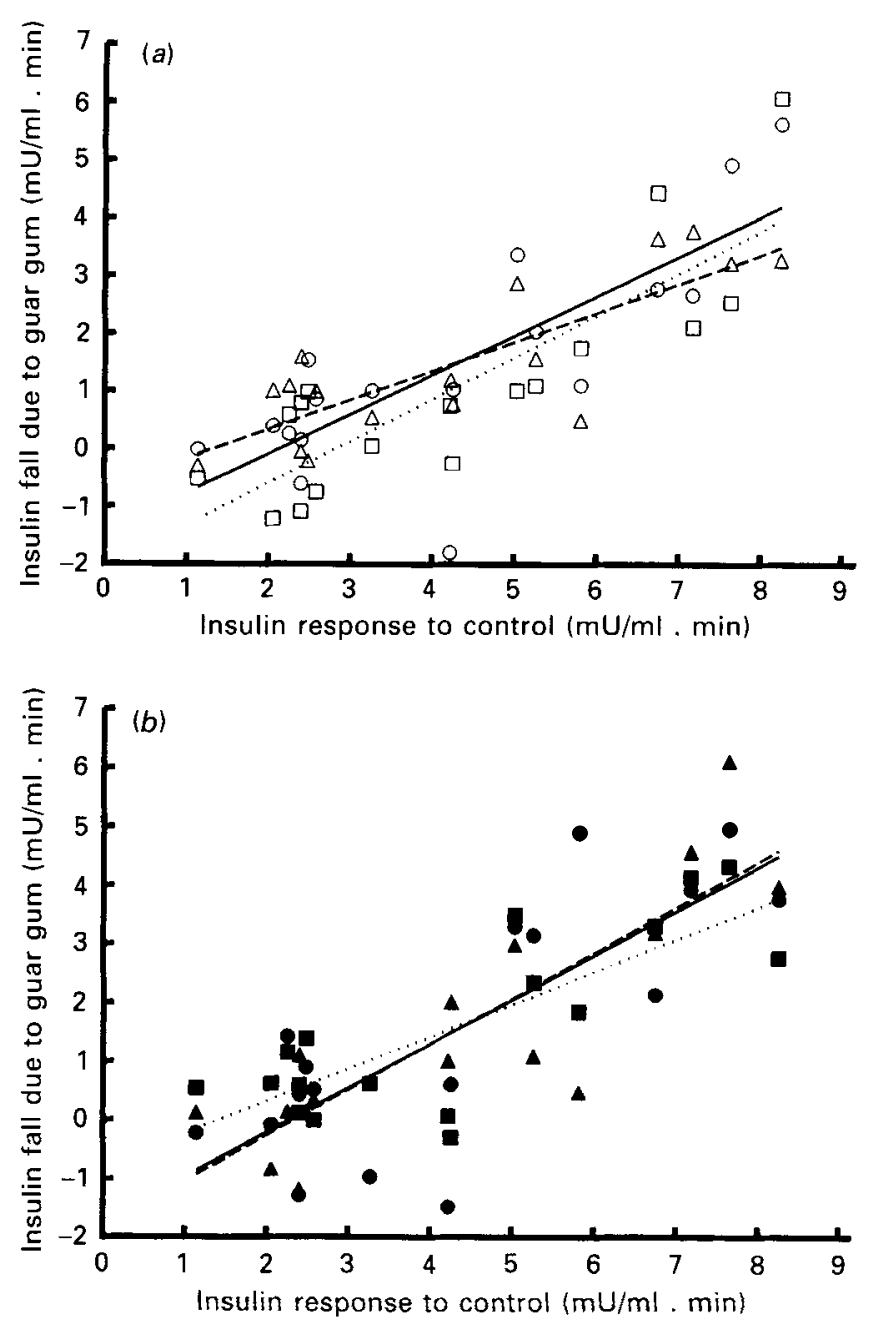

Fig. 3. Fall in integrated plasma insulin due to guar gum (i.e. control-guar bread) $v$. the integrated plasma insulin response to control. Experimental points $\left(n\right.$ 17) and regression lines for $(a) \mathrm{M} 150(-\mathrm{O}-), \mathrm{M} 90\left(--\Delta^{--}\right)$and M60 ( $\cdots \square \cdots)$ guar-gum flours; and $(b)$ coarse $(-\infty-)$, medium $\left(--\boldsymbol{\Delta}_{--)}\right.$and fine $(\cdots, \cdots)$ Guarem samples. No significant differences were found between the intercept and slope coefficients of the individual regression lines. Regression equation for all values in $(a)$ and $(b), Y=0.66$ (SE 0.05) X - 1.37 (SE 0.24). For details of guar-gum flours and Guarem samples, see p. 364 and Table 1.

levels for the six types of guar-gum bread were significantly lower than the control (see Table 4); all the guar-gum samples produced a mean decrease in integrated insulin of $35-37 \%$ of the control value, except the $\mathrm{M} 60$ (low $\mathrm{M}_{\mathrm{w}}$ ) which gave $25 \%$.

The degree of the insulin-sparing effect of all the guar-gum samples was found to be strongly dependent on the plasma insulin response to the control meal and was greatest in subjects with high insulin responses. Thus, highly significant positive correlations $(P<$ 0.0001 ) were found between the fall in integrated insulin due to guar gum (i.e. insulin response to control-insulin response to guar bread) and the integrated insulin response to the control bread meal (Fig. 3). Simple linear-regression models were fitted to the experimental data for each type of guar bread. No significant differences were found between the intercept and slope coefficients of the individual regression lines with either 

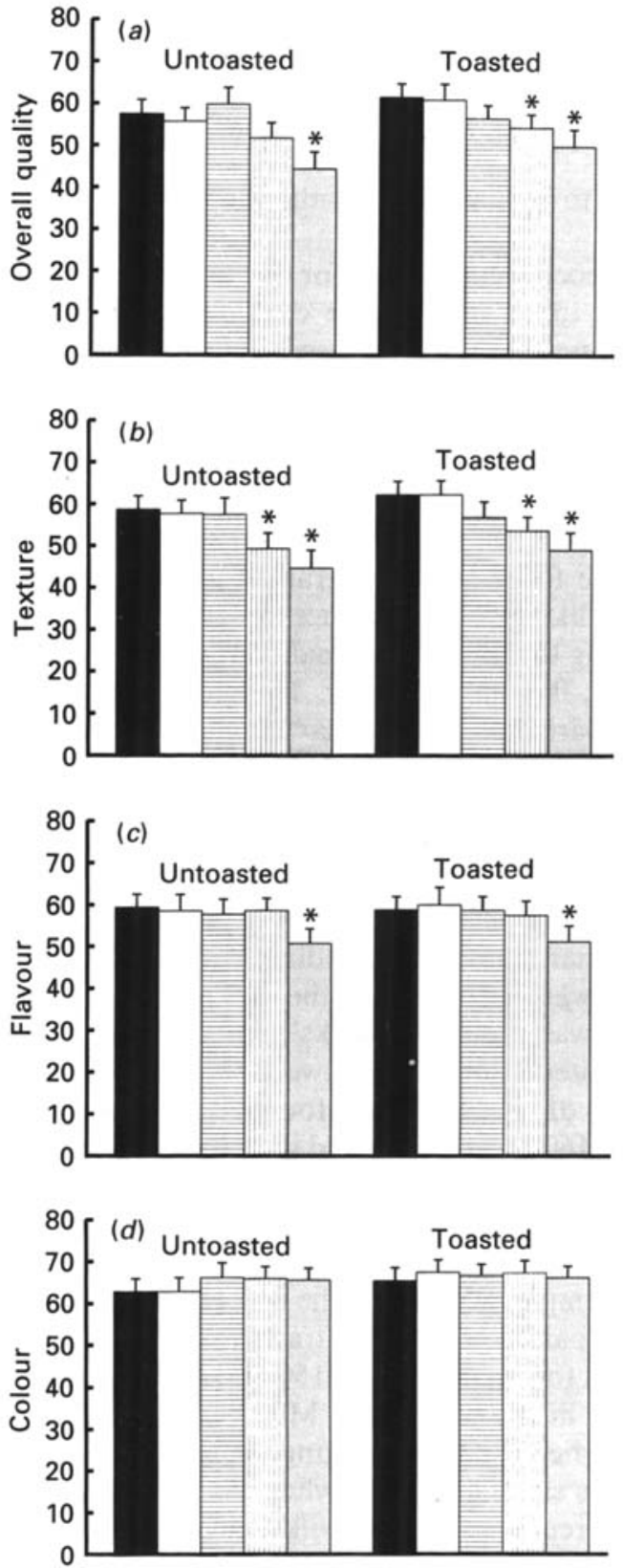

Fig. 4. Hedonic scores $(\mathrm{mm})$ for $(a)$ overall quality, $(b)$ texture, $(c)$ flavour, and $(d)$ colour of untoasted and toasted

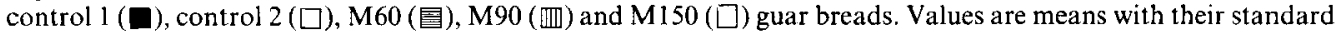
errors represented by vertical bars. * Mean values for experimental breads were significantly different from those for controls : $P<0.05$. For details of preparation of guar breads and their composition see p. 366 and Table 2 and for details of sensory procedures, see pp. 367-368. 
varying $\mathrm{M}_{\mathrm{w}}$ (Fig. 3(a)) or particle size (Fig. 3(b)), indicating a similar insulin-sparing trend for all types of guar gum. Values for all six guar breads were, therefore, analysed together, yielding the following linear equation:

$$
Y=0.66(\mathrm{SE} 0.05) X-1.37(\mathrm{SE} 0.24)
$$

where $Y$ is insulin fall due to guar gum $(\mathrm{mU} / \mathrm{ml}$. min) and $X$ is insulin response to control bread $(\mathrm{mU} / \mathrm{ml}$. $\mathrm{min})$.

The intercept and slope coefficients (\% SE) for this unified treatment are highly significant $(P<0.0001)$ and $r^{2} 0.63$. In terms of these coefficients, $Y$ is positive only when $X>$ approximately $2 \cdot 1$, indicating that an insulin-sparing response to guar gum is elicited only in subjects whose integrated insulin levels after the control meal exceed approximately $2.1 \mathrm{mU} / \mathrm{ml}$. min (and then increases in direct proportion to the control response).

\section{Sensory analysis}

The mean hedonic scores $(\mathrm{mm})$ of the assessors for the controls and three types of guar bread are illustrated in the form of a histogram (Fig. 4); low scores represent disliking and high scores represent liking. No differences in the mean scores between the control breads (calculated according to either batch quality or order of presentation) were observed for overall quality, texture, flavour or colour. Therefore, the scores for the controls were pooled for statistical comparison with the guar breads, but for presentation purposes the mean values for both controls have been included in Fig. 4.

Overall quality. Significant differences in scores (Wilks' lambda $0 \cdot 66 ; F$ ratio $5 \cdot 1$ on 3 and $30 \mathrm{df}, P<0.006)$ were found between the bread samples. The mean scores for the untoasted M150 (high $M_{w}$ ) bread, but not for the M90 (medium $M_{w}$ ) and M60 (low $M_{w}$ ) types, were significantly lower than the untoasted control (Fig. 4(a)). In the case of M60 bread, the mean score was higher than the corresponding control, but this difference was only significant when ANOVA was performed on the ranked values. No main effect of toasting (i.e. toasted $v$. untoasted) was observed (Wilks' lambda $0.97 ; F$ ratio 0.9 on 1 and $32 \mathrm{df}$, $P<0 \cdot 3$ ), but a significant interaction effect between toasting and bread type (Wilks' lambda $0.7 ; F$ ratio 4.2 on 3 and $30 \mathrm{df}, P<0.02$ ) was found. This can be explained by the decrease in mean score for toasted M60 bread compared with the untoasted M60 variety, in contrast to the non-significant increases found for toasted M90 and M150 breads compared with their corresponding untoasted types. A Student's $t$ test revealed a significant difference ( $t-4.5, P<0.0001$ ) in the ranked ratings, but not the scores, between the toasted M60 bread and the untoasted sample. Moreover, the $8 \%$ fall in the mean rating for the toasted M60 bread relative to the toasted control contrasts markedly with the $6 \%$ increase for the untoasted M60. The scores for the toasted M150 and M90 breads were significantly lower than the control, although in the case of the M90 variety this decrease was not found to be statistically significant when the ranked ratings were analysed. The decrease in score for the toasted M60 bread was significant only when the scores were ranked.

Texture. Significant differences in scores (Wilks' lambda $0.67 ; F$ ratio 5.0 on 3 and $30 \mathrm{df}$, $P<0.006)$ were found between the bread samples. The mean scores for the untoasted breads containing M150 and M90, but not M60, were significantly lower then the untoasted control, although in the case of the M90 type this effect was not statistically significant when the scores were ranked (Fig. $4(b)$ ). No main effect of toasting was observed (Wilks' lambda $0.94 ; F$ ratio 2.2 on 1 and $32 \mathrm{df}, P<0.15$ ). The scores for the toasted breads containing M150 and M90, but not M60, were, however, significantly lower than the toasted control.

Flavour. Significant differences in scores (Wilks' lambda $0.7 ; F$ ratio 4.27 on 3 and $30 \mathrm{df}$, $P<0.01$ ) were found between the bread samples. The mean scores for both the toasted and 
untoasted M150 breads were significantly lower than the corresponding controls, but no differences in scores were found between the other guar breads and the controls (Fig. 4(c)). No main effect of toasting was found (Wilks' lambda $0.99 ; F$ ratio 0.01 on 1 and 32 df, $P<0.95$ ).

Colour. No main effects were found for either bread type (Wilks' lambda $0.93 ; F$ ratio 0.72 on 3 and $30 \mathrm{df}, P<0.55$ ) or toasting (Wilks' lambda $0.97 ; F$ ratio 0.83 on 1 and $32 \mathrm{df}$, $P<0 \cdot 4$ ) (Fig. 4(d)).

\section{DISCUSSION}

The low blood glucose concentrations in response to the $75 \mathrm{~g}$ carbohydrate meals (Table 3 ), even at the 30 min peak time, were even lower than those reported in our earlier studies using breads containing $50 \mathrm{~g}$ or less carbohydrate (Ellis et al. 1981, 1988 a). The probable explanation is that in the present investigation, but not in the earlier studies, the subjects consumed fat spread with their bread and that this may have contributed to the weak blood glucose responses. Recently, we reported that biscuits containing a high concentration of butter (about $260 \mathrm{~g} / \mathrm{kg}$ biscuit) also elicited low blood glucose responses in healthy subjects (Ellis et al. 1988 b). Evidence for a glucose-lowering effect of fat per se has been provided by Collier \& O'Dea (1983) and Collier et al. (1984), who have demonstrated that the coingestion of large amounts of fat with a carbohydrate meal attenuates post-prandial hyperglycaemia in healthy subjects without a concomitant reduction in plasma insulin; a similar effect has been observed recently in NIDDM patients (Gulliford et al. 1989). It is not surprising, therefore, that in the present study a glucose-lowering effect with guar gum could not be detected when venous blood glucose concentrations were so low. Measurements of glucose concentrations in arterial or capillary blood, which normally are higher than those found in venous blood (Burrin \& Alberti, 1990), could have provided useful additional information about the glycaemic responses to our experimental meals. Nevertheless, in a study identical to the present one, wheat bread containing either low- or high- $\mathrm{M}_{\mathrm{w}}$ guar gum was found to reduce post-prandial hyperglycaemia in NIDDM patients whose fasting and peak venous blood glucose levels were about 8.6 and $15.6 \mathrm{mmol} / \mathrm{l}$, respectively (Gatenby et al. 1991).

Discrete measurements of blood glucose levels in the peripheral circulation over a $2-\mathrm{h}$ period are probably not a reliable index of the rate of glucose absorption in the small intestine (Rerat et al. 1984). Thus, measurements of the glucose concentration in the hepatic portal vein, which for obvious practical and ethical reasons cannot be obtained from human volunteers, would have provided more direct evidence of the effect of guar gum on the rate of glucose absorption. This has recently been confirmed by Roberts et al. (1991), who have reported that high- $\mathrm{M}_{w}$ guar gum (M150) significantly reduces the rate of glucose absorption and net insulin production in the portal vein of growing pigs; in this case, values for glucose absorption and insulin production were calculated from arterio-venous differences and portal blood flow measurements. The pigs used in the study were fed on meals containing guar gum at concentrations similar to those used in human studies, including the present one.

In the present study, the significant reductions in plasma insulin levels in response to the guar-bread meals (Table 4) were similar to the results obtained by Morgan et al. (1985), who also reported negligible changes in venous blood glucose levels in healthy individuals given a guar-containing meal. The substantial insulin-sparing effect achieved with all the guar breads did not appear to be influenced by large variations in the average $M_{w}$ (Table 1) and particle size distribution (Fig. 1) of guar gum. The mean integrated insulin values suggest that the low- $M_{w}$ guar gum (M60) was less effective than the higher- $M_{w}$ grades, but this difference was not statistically significant. Furthermore, the simple linear- 
regression lines (Fig. 3), illustrating the decrease in integrated insulin due to guar gum $v$. the integrated insulin response to the control meal, also provide evidence that all the guargum samples were equally effective. The unified linear model was found to be a more useful way of expressing the degree of insulin-lowering than simply comparing mean values, because it takes into account the wide variability in post-prandial insulin responses between subjects. It was then possible to estimate from this model that the insulin-sparing effect of guar gum was negligible in healthy subjects whose integrated insulin level in response to the control meal was less than about $2 \cdot 1 \mathrm{mU} / \mathrm{ml}$. min (Fig. 3).

Much of the effect of the guar-gum breads on post-prandial plasma insulin can probably be attributed to a reduced rate of glucose absorption in the small intestine, and also to a reduced stimulation of the entero-insular axis, notably the insulin-stimulating gastrointestinal hormone, gastric inhibitory polypeptide (Morgan et al. 1985, 1988), the secretion of which is directly related to the rate and site of glucose absorption (Morgan et al. 1988). The physico-chemical mechanism(s) by which guar gum inhibits the rate of absorption of carbohydrate and other nutrients is not completely understood. Current evidence indicates that the physiological activity of guar gum is dependent on its capacity to increase the viscosity of digesta, which then restricts the movement and release of sugars and other small molecules in the stomach and small intestine (Blackburn et al. 1984; Edwards et al. 1988; Edwards \& Read, 1990; Roberts et al. $1990 a, b$ ). A key factor is thought to be the way in which guar gum inhibits the physical mixing induced by peristaltic contractions in the small intestine, thereby reducing access of nutrients in the bulk phase to the epithelium (Edwards et al. 1988; Edwards \& Read, 1990).

In aqueous solutions of conformationally-disordered polysaccharides such as guar gum, viscosity is generated predominantly by interpenetration of individual chains (coils) to form an entangled network (Morris et al. 1981). The degree of space-occupancy (and, hence, the extent of entanglement and resulting viscosity) is determined by the (dimensionless) product of concentration (proportional to the number of chains present) and intrinsic viscosity (proportional to the volume that each chain occupies). For guar gum, the onset of coil-overlap and entanglement occurs (Robinson et al. 1982) when $c[\eta]$ exceeds approximately $2 \cdot 5$, and thereafter viscosity increases as approximately $(c[\eta])^{5}$, so that doubling either concentration or intrinsic viscosity (coil volume) increases viscosity by a factor of about 30 . Thus, at equivalent concentrations there should be a dramatic increase in viscosity through the series M60 < M90<M150 (Table 1), which is not reflected in the insulin-response values listed in Table 4. However, Low et al. (1986) have shown that the decrease in the rate of absorption of glucose from the jejunum of pigs is greater for M150 than for M60, as expected, although the difference was much smaller than would have been anticipated from the large difference in coil volume. The results of more recent experiments in pigs (Roberts et al. $1990 a, b$ ), using grades of guar gum identical to those tested in our present study, provide a plausible explanation of why we found that low- $M_{w}$ guar-gum flours were equally as effective as the high- $\mathbf{M}_{w}$ grade. Measurements on digesta taken from the jejunum of pigs with in-dwelling, re-entrant cannulas showed that the differences in viscosity between the high- and low- $M_{w}$ grades of guar gum were surprisingly small when compared with in vitro measurements. The origin of this behaviour was traced to substantial differences in the total volume of digesta passing through the jejunum, so that high- $\mathrm{M}_{\mathrm{w}}$ guar gum was diluted, either by increased endogenous secretions or reduced fluid absorption in the gut.

Guar gum may also reduce the rate of glucose absorption in the small intestine by impeding the diffusional transport of small molecules (e.g. oligosaccharides) through the relatively unstirred layer adjacent to the mucosal surface (Edwards et al. 1988; Edwards \& Read, 1990). The rate of diffusion of small molecules through a polymer (e.g. 
galactomannan) solution is dependent on the concentration of the polymer rather than its $M_{w}$ (Häglund et al. 1988). Thus, if a diffusional mechanism is dominant within the unstirred layer, a low- $M_{w}$ guar gum would be as effective as a high- $M_{w}$ grade in impairing the movement of nutrients. In general, however, diffusion rates are likely to be negligible in comparison with peristaltic mixing, and indeed Edwards et al. (1988), using a simple in vitro model, have recently reported that high- $\mathbf{M}_{w}$ guar gum has no effect on the diffusion of sodium ions.

A further explanation of the effectiveness of low- $M_{w}$ guar gum is that it may limit the rate of digestion of the starch component of bread, either by inhibiting gelatinization (e.g. by competing for available water; Holm et al. 1988) or by forming an enzyme-resistant barrier around the starch granules. Either effect would again be likely to depend on galactomannan concentration alone, rather than also involving $\mathbf{M}_{\mathrm{w}}$.

The importance of the rate and degree of hydration of guar gum in influencing physiological effectiveness has been previously underlined (O'Connor et al. 1981; Ellis et al. 1986; Ellis \& Morris, 1991). However, the present results (Table 4, Fig. 3) clearly indicate that the insulin-lowering action of the guar breads is unaffected by large differences in the in vitro rates of hydration of guar gum. This suggests that the coarse Guarem, which has a much slower rate of hydration than the fine fraction (Fig. 2), is sufficiently hydrated in the stomach and small intestine to slow down the digestion and absorption of carbohydrate. The in vitro hydration rate of the coarse Guarem (Fig. 2) is significantly greater than that of a mini-tablet preparation (Ellis \& Morris, 1991) found to be largely ineffective in improving blood glucose control (Holman et al. 1987; Baker, 1988). Little is known, however, about the in vivo hydration rate of Guarem and similar forms of guar gum, or about the degree of hydration (either in vivo or in vitro) required to decrease the post-prandial rise in blood glucose and plasma insulin. To investigate further the relationship between hydration and physiological action it would be useful to repeat the physiological part of the present study using guar-gum preparations with in vitro rates of hydration inferior to Guarem (Ellis \& Morris, 1991).

Another important factor in optimizing the efficacy of guar gum is likely to be the degree of mixing of the hydrated galactomannan polymer with the available carbohydrate (e.g. starch and its products of amylase (EC 3.2.1.1) action) in the gastrointestinal tract. This is likely to be influenced by the mode of administration of guar gum. Thus, impressive reductions in post-prandial blood glucose and plasma insulin levels have been reported by many research groups using either glucose drinks containing guar gum, or guar foods in which the galactomannan chains are likely to be in intimate contact with the available carbohydrate (Jenkins et al. 1976, 1977; Jarjis et al. 1984; Morgan et al. 1985; Ellis et al. $1988 \mathrm{~b}$ ). However, in some studies where the guar gum was consumed as a separate phase (often in the form of a drink) before the test meal, its effectiveness in improving blood glucose control was markedly diminished (Fuessl et al. 1986; Fairchild et al. 1990). In a recent acute study in healthy subjects, bread containing Guarem, as part of a highcarbohydrate breakfast meal, was more effective in reducing post-prandial insulin than Guarem in orange juice consumed immediately before the meal (Fairchild et al. 1990). Fuessl et al. (1986) have shown that granulated guar gum (Guarem) is more effective in reducing post-prandial hyperglycaemia in NIDDM patients when sprinkled on to mashed potato than when dispersed in water and taken immediately before the potato meal. The same group (Fuessl et al. 1987) subsequently demonstrated long-term improvements in carbohydrate and lipid metabolism of patients (NIDDM) who had sprinkled Guarem on to their meals. An inappropriate method of administering Guarem may explain why Uusitupa et al. (1989) recently failed to obtain long-term improvements in blood glucose control in poorly-controlled NIDDM patients. 
It has been reported previously that a high-viscosity grade of guar gum, with an ultimate viscosity (4.17 Pa s; Ellis \& Morris, 1991) similar to an equivalent concentration of M150 (Fig. 2), has an adverse effect on the hedonic rating of wheat bread, but this effect was observed only at guar gum concentrations $>32 \mathrm{~g} / \mathrm{kg}$ bread (Ellis $e$ t al. 1981, 1988 a). Breads containing lower concentrations of guar gum were given hedonic ratings identical to the control and also elicited useful reductions in post-prandial plasma insulin in healthy subjects (Ellis et al. 1981, 1988 a). It was also possible to estimate that the upper limit of acceptability for bread containing this type of guar gum was at a concentration of $60 \mathrm{~g} / \mathrm{kg}$, but it was not possible to identify from these studies what individual sensory characteristics were affected. Using a similar concentration of guar gum in the present study, it can be concluded firstly, that the deterioration in the overall hedonic rating of high- $M_{w}$ guar bread (both toasted and untoasted) can be attributed to poor texture and flavour (Fig. 4). The specific physical or chemical changes, or both, that contribute to the poor texture ratings have yet to be elucidated, although assessors in previous sensory tests have frequently recorded that during mastication guar bread has a sticky, gummy 'mouthfeel' (Ellis et al. 1981). Textural measurements using a cone penetrometer (Ellis \& Apling, 1983) and more recently an Instron (Dawoud, 1989) have shown that guar gum significantly softens the crumb of wheat bread and modifies other rheological variables. However, no attempt has yet been made to correlate these objective measurements to sensory analysis data. Secondly, the adverse flavour rating of the M150 guar bread is unlikely to be caused by taints from the guar-gum flour per se, because all the guar-gum samples are highly purified preparations with no noticeable off-flavour. The difference in $\mathbf{M}_{\mathrm{w}}$ between the M150 guar gum and the low-viscosity grades is a more likely explanation for the wide variability in flavour ratings. Viscous polysaccharides such as guar gum are known to mask the magnitude of taste intensity (e.g. sweetness) and this effect appears to be related to the degree of viscosity (Baines \& Morris, 1987). However, the evidence for this relationship was obtained from studies of aqueous solutions of viscous polysaccharides rather than foods such as bread.

Finally, the results clearly show that significant improvements in the quality of guar bread, specifically texture and flavour, can be achieved by using low- $\mathrm{M}_{\mathrm{w}}$ guar gum (Fig. 4). This was most noticeable with the M60 grade, which according to the ranked ratings (but not the raw scores) was even more acceptable than the control. This result is consistent with findings from baking trials (Apling \& Ellis, 1982), which have shown that marked improvements in the quality of guar bread (e.g. crumb structure) can be obtained by using low- $\mathrm{M}_{\mathrm{w}}$ guar gum in the recipe, and is similar to the hedonic scores reported for bread containing low concentrations of high- $\mathbf{M}_{\mathrm{w}}$ guar gum $(<32 \mathrm{~g} / \mathrm{kg}$ bread; Ellis et al. 1981, 1988 a). Although mean hedonic scores and ranks for all toasted breads, except the M60 guar-gum type, were higher than for the untoasted breads, no statistically significant toasting effect was found, in contrast to earlier subjective observations that toasting improves the quality of guar bread (Ellis et al. 1988 a). However, a slightly more complex picture emerges when the interaction effect between bread and toasting is taken into account. This interaction effect can be attributed to the fact that the overall quality (ranked scores only) of bread containing M60 is decreased by toasting, in marked contrast to the general (but non-significant) trend of all the other toasted breads producing higher scores than the untoasted samples. At present we have no explanation for this effect.

In conclusion, it has been demonstrated that the insulin-sparing effect of guar bread in healthy subjects is unaffected by wide variations in $\mathbf{M}_{\mathbf{w}}$ and particle-size of guar gum. Further work is needed to determine more precisely the range of doses and molecular weights of guar gum which induce significant changes in carbohydrate metabolism. The highly palatable nature of low- $\mathrm{M}_{\mathrm{w}}$ guar bread and its effectiveness in reducing post- 
prandial hyperglycaemia in NIDDM patients (Gatenby et al. 1991) indicate that such a product is worthy of study as a therapeutic aid in the long-term management of diabetes.

The authors thank Ms Elizabeth Bowey, Ms Karen Martin, Dr Anthony Leeds, Mr Vernon Dawes (Pharmacy) and Dr David Thomson (University of Reading) for their expert assistance, and Dr Linda Morgan (University of Surrey) for helpful discussions during the preparation of the manuscript. We are particularly grateful to $\mathrm{Mr}$ Peter J. Milligan for his advice on statistics. Mr Reg Hopkins (Meyhall Chemical, UK) and Mr Ron Levin (Rybar Laboratories, UK) supplied the guar flour (Meyprogat samples) and guar granules (Guarem), respectively. Financial support was provided by Snow Brand Milk Products Company Ltd, Tokyo, Japan.

\section{REFERENCES}

Apling, E. C. \& Ellis, P. R. (1982). Guar bread: concept to application. Chemistry and Industry pp. 950-954.

Aro, A., Uusitupa, M., Voutilainen, E., Hersio, K., Korhonen, T. \& Siitonen, O. (1981). Improved diabetic control and hypo-cholesterolaemic effect induced by long-term dietary supplementation with guar gum in type 2 (insulin independent) diabetes. Diabetologia 21, 29-33.

Baines, Z. V.\& Morris, E. R. (1987). Flavour/taste perception in thickened systems: the effect of guar gum above and below $c^{*}$. Food Hydrocolloids 1, 197-205.

Baker, P. (1988). Placebo-controlled trial of guar in poorly controlled Type II diabetes. Practical Diabetes 5 , 36-38.

Blackburn, N. A., Redfern, J. S., Jarjis, H., Holgate, A. M., Hanning, I., Scarpello, J. H., Johnson, I. T. \& Read, N. W. (1984). The mechanism of action of guar gum in improving glucose tolerance in man. Clinical Science 66, $329 \cdots 336$.

Burrin, J. M. \& Alberti, K. G. M. M. (1990). What is blood glucose: can it be measured? Diabetic Medicine 7 , 199-206.

Collier, G., McLean, A. \& O'Dea, K. (1984). Effect of co-ingestion of fat on the metabolic responses to slowly and rapidly absorbed carbohydrates. Diabetologia 26, 50-54.

Collier, G. \& O'Dea, K. (1983). The effect of coingestion of fat on the glucose, insulin, and gastric inhibitory polypeptide responses to carbohydrate and protein. American Journal of Clinical Nutrition 37, 941-944.

Dawoud, F. M. (1989). High-fibre wheat breads for the management of diabetes: product development, physiological testing and sensory evaluation. PhD Thesis, University of London.

Ebling, P., Hannele, Y.-J., Aro, A., Helve, E., Sinisalo, M. \& Koivisto, V. A. (1988). Glucose and lipid metabolism and insulin sensitivity in type 1 diabetes: the effect of guar gum. American Journal of Clinical Nutrition 48, 98-103.

Edwards, C. A., Johnson, I. T. \& Read, N. W. (1988). Do viscous polysaccharides slow absorption by inhibiting diffusion or convection? European Journal of Clinical Nutrition 42, 307-312.

Edwards, C. A. \& Read, N. W. (1990). Fibre and small intestinal function. In Dietary Fibre Perspectives 2 , pp. 52-75 [A. R. Leeds, editor]. London: John Libbey.

Egan, H., Kirk, R. S. \& Sawyer, R. (1981). Pearson's Chemical Analysis of Foods, 8th ed. Edinburgh: Churchill Livingstone.

Ellis, P. R. \& Apling, E. C. (1983). The development and acceptability of guar-bran bread. In Proceedings of the 7th World Cereal and Bread Congress, Prague, 1982, pp. 1121-1126 [J. Holas and J. Kratochvil, editors]. Amsterdam: Elsevier.

Ellis, P. R., Apling, E. C., Leeds, A. R. \& Bolster, N. R. (1981). Guar bread: acceptability and efficacy combined. Studies on blood glucose, serum insulin and satiety in normal subjects. British Journal of Nutrition 46, $267-276$.

Ellis, P. R., Burley, V. J., Leeds, A. R. \& Peterson, D. B. (1988a). A guar-enriched wholemeal bread reduces postprandial glucose and insulin responses. Journal of Human Nutrition and Dietetics 1, 77-84.

Ellis, P. R., Kamalanathan, T., Dawoud, F. M., Strange, R. N. \& Coultate, T. P. (1988b). Evaluation of guar biscuits for use in the management of diabetes: tests of physiological effects and palatability in non-diabetic volunteers. European Journal of Clinical Nutrition 42, 425-435.

Ellis, P. R. \& Morris, E. R. (1991). Importance of the rate of hydration of pharmaceutical preparations of guar gum: a new in vitro monitoring method. Diabetic Medicine 8, 378-381.

Ellis, P. R., Morris, E. R. \& Low, A. G. (1986). Guar gum: the importance of reporting data on its physicochemical properties. Diabetic Medicine 3, 490-491.

Englyst, H., Wiggins, H. S. \& Cummings, J. H. (1982). Determination of the non-starch polysaccharides in plant foods by gas-liquid chromatography of constituent sugars as alditol acetates. Analyst 107, 307-318.

Fairchild, R. M., Daniels, C. E. J., Ellis, P. R., Naqvi, S. H. M., Kwan, R. M. F. \& Mir, M. A. (1990). Effect of two types of guar gum in solid and liquid foods on postprandial blood glucose, plasma insulin and C-peptide in healthy subjects. Proceedings of the Nutrition Society 49, 54A. 
Fuessl, S., Adrian, T. E., Bacarese-Hamilton, A. J. \& Bloom, S. R. (1986). Guar in NIDD: effect of different modes of administration on plasma glucose and insulin responses to a starch meal. Practical Diabetes $\mathbf{3}$, $258-260$.

Fuessl, H. S., Williams, G., Adrian, T. E. \& Bloom, S. R. (1987). Guar sprinkled on food: effect on glycaemic control, plasma lipids and gut hormones in non-insulin-dependent diabetic patients. Diabetic Medicine 4, $463-468$.

Gatenby, S. J., Ellis, P. R., Morgan, L. M., Dawoud, F. M. \& Judd, P. A. (1991). The effect of low, medium and high molecular weight grades of guar gum on postprandial blood glucose and plasma insulin in non-insulindependent diabetics. Proceedings of the Nutrition Society 50, 58A.

Gulliford, M. C., Bicknell, E. J. \& Scarpello, J. H. (1989). Differential effect of protein and fat ingestion on blood glucose responses to high- and low-glycemic-index carbohydrates in noninsulin-dependent diabetic subjects. American Journal of Clinical Nutrition 50, 773-777.

Häglund, B.-O., Elisson, M. \& Sundelöf, L.-O. (1988). Diffusion permeability in concentrated polymer solutions. The fluorescein-dextran-water system. Chemica Scripta 28, 129-131.

Holm, J., Lundquist, I., Björk, I., Eliasson, A.-C. \& Asp, N.-G. (1988). Degree of starch gelatinisation, digestion rate of starch in vitro, and metabolic responses in rats. American Journal of Clinical Nutrition 47, $1010-1016$.

Holman, R. R., Steemson, J., Darling, P. \& Turner, R. C. (1987). No glycaemic benefit from guar administration in NIDDM. Diabetes Care 10, 68-71.

Jarjis, H. A., Blackburn, N. A., Redfern, J. S. \& Read, N. W. (1984). The effect of ispaghula (Fybogel and Metamucil) and guar gum on glucose tolerance in man. British Journal of Nutrition 51, 371-378.

Jenkins, D. J. A., Leeds, A. R., Gassull, M. A., Cochet, B. \& Alberti, K. G. M. M. (1977). Decrease in postprandial insulin and glucose concentrations by guar and pectin. Annals of Internal Medicine 86, 20-23.

Jenkins, D. J. A., Leeds, A. R., Gassull, M. A., Wolever, T. M. S., Goff, D. V.,. Alberti, K. G. M. M. \& Hockaday, T. D. R. (1976). Unabsorbable carbohydrates and diabetes: decreased post-prandial hyperglycaemia. Lancet ii, $172-174$.

Land, D. G. \& Shepherd, R. (1988). Scaling and ranking methods. In Sensory Analysis of Foods, pp. 155-185 [J. R. Piggott, editor]. London: Elsevier.

Lauer, O. (1966). Grain Size Measurements on Commercial Powders. Ausberg: Alpine AG Ausberg.

Low, A. G., Zebrowska, T., Heppell, L. M. J. \& Smith, H. A. (1986). Influence of wheat bran, cellulose, pectin and low or high viscosity guar gum on glucose and water absorption from the pig jejunum. Proceedings of the Nutrition Society 45, 55A.

Morgan, L. M., Flatt, P. R. \& Marks, V. (1988). Nutrient regulation of the entero-insular axis and insulin secretion. Nutrition Research Reviews 1, 79-97.

Morgan, L. M., Tredger, J. A., Madden, A., Kwasowski, P. \& Marks, V. (1985). The effect of guar gum on carbohydrate-, fat- and protein-stimulated gut hormone secretion: modification of post-prandial gastric inhibitory polypeptide and gastrin responses. British Journal of Nutrition 53, 467-475.

Morris, E. R. (1984). Rheology of hydrocolloids. In Gums and Stabilisers for the Food Industry 2, pp. 57-78 [G. O. Philips, D. J. Wedlock and P. A. Williams, editors]. Oxford: Pergamon Press.

Morris, E. R., Cutler, A. N., Ross-Murphy, D. A., Rees, D. A. \& Price, J. (1981). Concentration and shear rate dependence of viscosity in random coil polysaccharide solutions. Carbohydrale Polymers 1, 5-21.

O'Connor, N., Tredger, J. \& Morgan, L. (1981). Viscosity differences between various guar gums. Diabetologia 20, 612-615.

Paul, A. A. \& Southgate, D. A. T. (1978). McCance \& Widdowson's The Composition of Foods, 4th ed, London: H.M. Stationery Office.

Peterson, D. B., Ellis, P. R., Baylis, J. M., Fielden, P., Ajodhia, J., Leeds, A. R. \& Jepson, E. M. (1987). Low dose guar in a novel food product: improved metabolic control in non-insulin-dependent diabetes. Diabetic Medicine 4, 111-115.

Rerat, A. A., Vaissade, P. \& Vaugelade, P. (1984). Absorption kinetics of some carbohydrates in conscious pigs. 1. Qualitative aspects. British Journal of Nutrition 51, 505-515.

Roberts, F. G., Low, A. G., Young, S., Smith, H. A. \& Ellis, P. R. (1991). The effect of high viscosity guar gum flour on the rate of glucose absorption and net insulin production in the portal blood of the pig. Proceedings of the Nutrition Society 50, 72A.

Roberts, F. G., Smith, H. A., Low, A. G. \& Ellis, P. R. (1990a). Influence of wheat breads containing guar flour supplements of high and low molecular weights on viscosity of jejunal digesta in the pig. In Dietary Fibre: Chemical and Biological Aspects, pp. 164-168 [D. A. T. Southgate, K. Waldren, I. T. Johnson and G. R. Fenwick, editors]. Cambridge: The Royal Society of Chemistry.

Roberts, F. G., Smith, H. A., Low, A. G., Ellis, P. R., Morris, E. R. \& Sambrook, I. E. (1990b). Influence of guar gum flour of different molecular weights on viscosity of jejunal digesta in the pig. Proceedings of the Nutrition Society 49, 53A.

Robinson, G., Ross-Murphy, S. B. \& Morris, E. R. (1982). Viscosity-molecular weight relationships, intrinsic chain flexibility and dynamic solution properties of guar galactomannan. Carbohydrate Research 107, 17-32.

SAS Institute Inc. (1985). SAS User's Guide: Statistics, 5th ed. Cary, North Carolina: SAS Institute Inc.

Seaman, J. K. (1980). Guar gum. In Handbook of Water-soluble Gums and Resins, pp. 1-18 [R. L. Davidson, editor]. New York: McGraw-Hill. 
Soeldner, J. S. \& Slone, D. (1965). Critical variables in the radioimmunoassay of serum insulin using the double antibody technique. Diabetes 14, 771-779.

Thomson, D. M. H. \& McEwan, J. A. (1985). Predictive modelling and evaluation of food acceptability. In Consumer Behaviour Research and Marketing of Agricultural Products, pp. $63-82$ [J. E. R. Frijters, editor]. The Hague: National Council for Agricultural Research.

Uusitupa, M., Siitonen, O., Savolainen, K., Silvasti, M., Penttilä, I. \& Parviainen, M. (1989). Metabolic and nutritional effects of long-term use of guar gum in the treatment of noninsulin-dependent diabetes of poor metabolic control. American Joumal of Clinical Nutrition 49, 345-351.

Werner, W., Rey, H. G. \& Wielinger, H. (1970). On the properties of a new chromagen for the determination of glucose in blood according to the GOD/POD methods (German). Zeitschrift für Analytische Chemie 252 , 224-228. 